\title{
Design of the Insurance Contract Based on the Weather Indices of Chilling Injury in Litchi and Demonstration Application
}

\author{
Chunyi Wang ${ }^{1,2}$,Jinghong Zhang ${ }^{2,3}$,Yajie Zhang ${ }^{2,3}$, Haijing Huang ${ }^{2,3}$, Xiufen Che $^{2,3}$ \\ 1. Hainan Institute of Meteorological Sciences, \#60 Haifu Road, Haikou 570203, Hainan, China \\ 2. Key Laboratory of Meteorological Disaster Prevention and Reduction in the South China Sea, \#60 \\ Haifu Road, Haikou 570203, Hainan, China \\ 3. Hainan Climate Center, \#60 Haifu Road, Haikou 570203, Hainan, China
}

\section{荔枝寒害气象指数保险合同设计及示范应用}

\author{
王春乙 ${ }^{1,2}$ 张京红 $^{2,3}$, 张亚杰 ${ }^{2,3}$, 黄海静 ${ }^{2,3}$, 车秀芬 ${ }^{2,3}$ \\ 1. 海南省气象科学研究所, 海口 570203 , 中国 \\ 2 南海气象防灾减灾重点实验室, 海口 570203, 中国 \\ 3 海南省气候中心, 海口 570203, 中国
}

\begin{abstract}
Chilling injuries severely affect and restrict the litchi production in Hainan. Accordingly, the studies on the design of insurance contracts based on the weather indices and will be of great significance for transferring disaster risks, reducing the losses of planters. Using the data of litchi yield from 1990 to 2010 as well as the meteorological data from 1961 to 2010 in Hainan, the yield risk distribution model was developed using the extreme value theory. Subsequently, the pure premium rates in all counties or cities were determined. Finally, the insurance products and contracts with different deductibles were designed. With the chilling damage of litchi encountered in Hainan Province in 2014, the paper applied the insurance contract in Haikou and Chengmai, the result of error
\end{abstract}

第一作者: 王春乙, 男, 辽宁人, 研究员, 硕、博 士生导师, 主要从事农业气象研究。Email: wcy@cms1924.org。

基金项目: 国家自然科学基金项目（41175096）、 海南省自然科学基金项目（414198）共同资助。 testing indicate that simulation of the chilling injury index to litchi yield reduction rate was accurate, and the determination of the premium rate was scientific and reasonable. The insurance contracts based on the weather indices with different deductibles are designed according to the requirements of the insurers at different regions with different risks. They can provide technical supports for the establishment and improvement of agricultural insurance schemes for litchi in Hainan.

Keywords: chilling injury of litchi, insurance contract based on the weather indices, demonstration application

\section{摘要}

海南寒害严重影响和制约荔枝种植业的发展, 开展荔枝寒害气象指数保险合同设计, 对于抵 御气象灾害风险, 增加种植户收入具有重要意 义。利用海南岛 18 个市 (县) 1990-2010 年 的荔枝产量数据和 1961-2010 年的气象数据, 应用极值理论构建了产量风险分布模型厘定 各市 (县) 纯保险费率, 设计了基于不同免赔 


\section{Risk Analysis and Crisis Response in Big Data Era (RAC-16)}

额的保险产品及合同。本研究结合 2014 年海 南省荔枝生产过程中遭遇的低温冷害, 对设计 的保险合同在海口和澄迈进行了示范应用, 从 误差检验来看, 寒害指数对荔枝寒害减产率的 模拟较为准确, 费率厘定结果比较科学合理。 基于多种免赔额的气象指数保险合同针对不 同风险地区投保户需求设计, 为海南建立和完 善荔枝政策性农业保险方案提供技术支撑。

关键字: 荔枝寒害，气象指数保险合同，示范 应用

\section{1. 引言}

海南是世界上具有得天独厚地理、气候条 件的荔枝主产区，也是我国荔枝原产地之一， 种植面积呈现逐年增长的趋势 ${ }^{[1]}$ 。荔枝对温度 的要求较严, 在 $10^{\circ} \mathrm{C}$ 以上才能开花, $18 \sim 24^{\circ} \mathrm{C}$ 开花最盛 ${ }^{[2]}$ ，期间如遭遇低温则易引发寒害而 导致减产 ${ }^{[3]}$ 。海南冬季常遭受北方冷空气侵袭, 1962、1975、1996、2005 和 2008 年均出现了 严重降温的天气过程 ${ }^{[4]}$, 影响了荔枝的正常开 花而形成寒害, 严重制约了荔枝种植业的发展, 因此深入研究荔枝寒害气象指数保险费率厘 定、保险产品及合同设计，能够有效转移荔枝 寒害风险，保障农户利益。

国外在农业保险方面开展研究较早, 初期 采用传统农业保险，存在各种弊病 ${ }^{[5-8]}$, 后来 逐渐被区域产量指数 ${ }^{[9]}$ 和天气指数保险 ${ }^{[10]}$ 产 品所代替。天气指数保险具有不需要逐一定损、 道德风险和逆向选择问题易于控制、理赔速度 快等优点, 被看作是在发展中国家更可行的风 险管理产品 ${ }^{[11-12]}$ 。国内农业气象保险起步较晚, 但保费规模和保险覆盖面增长较快 ${ }^{[13]}$ 。国内学 者在保险产品的费率厘定 ${ }^{[14-15]}$, 以及区域产量 指数保险 ${ }^{[14,16]}$ 和天气指数保险 ${ }^{[17-21]}$ 方面做了大 量研究。气象指数保险产品及合同设计的核心 是保险费率厘定, 主要方法有经验费率法和单 产风险分布模型法 ${ }^{[22]}$, 传统农业保险大都采用 经验费率法, 主观性较大, 指数保险产品多采 用单产风险分布模型法, 数学推理性强, 理论 严谨, 计算结果更为准确客观 ${ }^{[23]}$ 。

海南是我国热带水果的主产区, 关于热带 水果的保险研究开展较少。前人开展了海南岛 香蕉和芒果寒害纯保险费率研究 ${ }^{[22,24]}$, 但荔枝 寒害气象指数保险方面的研究尚未开展。本文
以海南省荔枝寒害作为研究对象, 从海南省农 业保险经营的实际需要出发, 以天气指数保险 产品设计为目标, 设计基于不同免赔额的荔枝 寒害气象指数保险产品及合同, 并针对 2014 年海南岛发生的寒害过程进行示范应用。

\section{2. 资料与方法}

2.1 资料

荔枝 1990-2010 年总产量、种植面积和收 获面积资料来自海南省统计局；1961-2010 年 的热带气旋、平均气温、最低气温、最高气温、 降水量等气象数据来自海南省气候中心; 逐月 的综合气象干旱指数资料来自海南省气象科 学研究所; 灾情资料来源于《中国气象灾害大 典・海南卷》。

\section{2 气象指数保险合同设计}

气象指数保险合同共包括合同的类型、合 同期官方气象站数据、确定气象保险指数、诱 发系数、单向的或者是双向的赔付、费率, 其 核心部分是厘定费率 ${ }^{[10,23]}$ 。本研究采用极值理 论确定荔枝寒害减产的概率分布, 计算以县为 单位的荔枝保险费率，建立荔枝气象指数保险 合同。

\section{3. 结果}

\section{1 致灾因子和减产率}

由于海南荔枝寒害是中弱冷空气多次补 充累积造成的, 因此仅考虑过程降温幅度和最 低气温并不全面。本文以最大降温幅度、极端 最低气温、日最低气温 $\leqslant 10^{\circ} \mathrm{C}$ 持续日数和 $\leqslant 10^{\circ} \mathrm{C}$ 积寒为致灾因子, 计算综合寒害指数, 公式如 下:

$$
D_{C}=\sum_{i=1}^{4} a_{i} X_{i}
$$

式中, $D_{c}$ 为综合寒害指数, $X_{I}$ 为最大降温 幅度, $X_{2}$ 为极端最低气温, $X_{3}$ 为日最低气温 $\leqslant 10^{\circ} \mathrm{C}$ 持续日数, $X_{4}$ 为 $\leqslant 10^{\circ} \mathrm{C}$ 积寒, $a_{1} 、 a_{2} 、 a_{3} 、 a_{4}$ 为相应因子的权重系数, 由主成分分析法确定。

荔枝种植在保险期内出现寒害过程 (寒害 指数大于 0 ), 则需计算其单产减产率, 并与 农户购买的保险产品的免赔额进行比较, 如高 于免赔额则按照实际减产率进行赔偿。由寒害 导致的单产减产率可通过历史的寒害指数与 单产减产率建立回归方程进行估算。本研究统 计了 1961-2010 年海南岛 18 个市 (县) 的寒 
Risk Analysis and Crisis Response in Big Data Era (RAC-16)

害指数 $D_{c}$ 和荔枝单产减产率 $y$, 得到回归方程 如下:

$$
y=0.0436 D_{C}+0.0407
$$

\section{2 费率厘定}

\section{2 .1 荔枝寒害的产量风险分布}

寒害是荔枝主产区荔枝生产中的极端气 候事件, 所以采用极值理论分析荔枝寒害气象 风险。本研究采用Weibull 分布模拟荔枝寒害 单产风险分布。

$$
f(x ; m, \eta, \gamma)=\left\{\begin{array}{cc}
\frac{m}{\eta^{m}}(x-\gamma)^{m-1} \exp \left(-\left(\frac{x-\gamma}{\eta}\right)^{m}\right) & x \geq \gamma \\
0 & x<\gamma
\end{array}\right.
$$

表 1 荔枝的单产风险分布参数

\begin{tabular}{cccccccc}
\hline 市县 & $\mathrm{m}$ & $\eta$ & $\gamma$ & 市县 & $\mathrm{m}$ & $\eta$ & $\gamma$ \\
\hline 海口 & 0.51240 & 0.03365 & 0.03231 & 临高 & 0.50258 & 0.02385 & 0.03225 \\
三亚 & - & - & - & 儋州 & 0.58965 & 0.04988 & 0.03248 \\
五指山 & 0.42691 & 0.02077 & 0.03237 & 东方 & - & - & - \\
文昌 & 0.48406 & 0.01292 & 0.03225 & 乐东 & 0.51281 & 0.00946 & 0.03231 \\
琼海 & 0.56659 & 0.01976 & 0.03237 & 琼中 & 0.54178 & 0.04356 & 0.03225 \\
万宁 & 0.47253 & 0.00902 & 0.03225 & 保亭 & 0.53134 & 0.00803 & 0.03284 \\
定安 & 0.46815 & 0.02309 & 0.03231 & 陵水 & 0.31008 & 0.00181 & 0.03242 \\
屯昌 & 0.51254 & 0.03317 & 0.03225 & 白沙 & 0.61128 & 0.05229 & 0.03237 \\
澄迈 & 0.62438 & 0.04124 & 0.03242 & 昌江 & 0.55499 & 0.02032 & 0.03225 \\
\hline 注“一”表示夫发牛寒害或夫种植荔枝 & & & & &
\end{tabular}

\section{2 .2 荔枝寒害的纯保险费率}

保险费率由纯费率和附加费率组成。附加 费率是保险人经营保险业务的各项费用和合 理利润与纯保费的比率, 它在保险费率中处于 次要地位。本文只对纯保险费率进行探讨。厘 定荔枝寒害的纯保险费率, 采用公式 $4^{[22]}$ 。

$$
R=\frac{E[l o s s]}{\lambda \mu}=\int_{F}^{1} x f(x) d x
$$

式中, $R$ 为纯保险费率; $\lambda$ 为保障比例, 取值 $100 \%^{[22]}$; $\mu$ 为预期单产，取值 $100 \%^{[22]}$; $E[\operatorname{los} S]$ 为产量损失的数学期望; $X$ 为 1961-2010 年各市 (县) 荔枝的寒害减产率序 列; $f(x)$ 为单产风险的密度函数; $F$ 为保险免 赔额, 减产低于免赔额不赔偿, 设置免赔额可 以降低道德风险。

将荔枝寒害减产序列和单产风险分布密 度函数代入公式 4, 计算 18 个市 (县) 免赔 额依次为 4\%、6\%、8\%和 10\%时的纯保险费率(表
2-5)。高免赔额对应的纯保险费率低, 但也 意味着高风险。

表 2-5 是不同免赔额下的荔枝寒害纯保 险费率。免赔额为 4\%时, 费率在 1.91\%-9. 65\% 之间; 免赔额为 $6 \%$ 时, 费率在 $1.37 \%-8.55 \%$ 之间; 免赔额为 $8 \%$ 时, 费率在 $0.97 \%-7.73 \%$ 之间; 免赔额为 $10 \%$ 时, 费率在 $0.69 \%-7.02 \%$ 之间。白沙、䛓州和琼中的保险费率最高, 均 超过 $6 \%$, 说明中部和西北部发生荔枝寒害减 产的风险较高。

纯保险费率高值区为中部山区的琼中、屯 昌和白沙, 西部的儋州, 以及北部的海口和澄 迈, 且在 4 种免赔额中均高于 $5 \%$, 其中白沙 最高, 表明这些地区为荔枝寒害风险较高地区, 且种植技术或防灾减灾能力较差; 纯保险费率 次高值区为中部五指山、北部定安和临高, 其 寒害风险也较高; 纯保险费率低值区在南部和 东部, 其中南部三亚历史上无寒害记录, 表明 
Risk Analysis and Crisis Response in Big Data Era (RAC-16)

表 2 荔枝寒害的纯保险费率（免赔额 $=4 \%$ )

\begin{tabular}{cccccc}
\hline 市县 & $\mathrm{R}(\%)$ & 市县 & $\mathrm{R}(\%)$ & 市县 & $\mathrm{R}(\%)$ \\
\hline 海口 & 7.85 & 定安 & 6.48 & 乐东 & 3.00 \\
三亚 & - & 屯昌 & 7.77 & 琼中 & 9.04 \\
五指山 & 6.52 & 澄迈 & 8.02 & 保亭 & 2.61 \\
文昌 & 4.07 & 临高 & 6.24 & 陵水 & 1.91 \\
琼海 & 4.90 & 儋州 & 9.53 & 白沙 & 9.65 \\
万宁 & 3.15 & 东方 & - & 昌江 & 5.08 \\
\hline
\end{tabular}

表 3 荔枝寒害的纯保险费率（免赔额 $=6 \%$ ）

\begin{tabular}{cccccc}
\hline 市县 & $\mathrm{R}(\%)$ & 市县 & $\mathrm{R}(\%)$ & 市县 & $\mathrm{R}(\%)$ \\
\hline 海口 & 6.79 & 定安 & 5.45 & 乐东 & 1.90 \\
三亚 & - & 屯昌 & 6.70 & 琼中 & 7.99 \\
五指山 & 5.57 & 澄迈 & 6.82 & 保亭 & 1.46 \\
文昌 & 3.01 & 临高 & 5.15 & 陵水 & 1.37 \\
琼海 & 3.66 & 儋州 & 8.43 & 白沙 & 8.55 \\
万宁 & 2.15 & 东方 & - & 昌江 & 3.86 \\
\hline
\end{tabular}

表 4 荔枝寒害的纯保险费率（免赔额 $=8 \%$ ）

\begin{tabular}{cccccc}
\hline 市县 & $\mathrm{R}(\%)$ & 市县 & $\mathrm{R}(\%)$ & 市县 & $\mathrm{R}(\%)$ \\
\hline 海口 & 6.08 & 定安 & 4.83 & 乐东 & 1.38 \\
三亚 & - & 屯昌 & 6.00 & 琼中 & 7.24 \\
五指山 & 5.00 & 澄迈 & 5.96 & 保亭 & 0.97 \\
文昌 & 2.44 & 临高 & 4.47 & 陵水 & 1.14 \\
琼海 & 2.93 & 儋州 & 7.63 & 白沙 & 7.73 \\
万宁 & 1.65 & 东方 & - & 昌江 & 3.15 \\
\hline
\end{tabular}

表 5 荔枝寒害的纯保险费率（免赔额=10\%）

\begin{tabular}{cccccc}
\hline 市县 & $\mathrm{R}(\%)$ & 市县 & $\mathrm{R}(\%)$ & 市县 & $\mathrm{R}(\%)$ \\
\hline 海口 & 5.52 & 定安 & 4.34 & 乐东 & 1.06 \\
三亚 & - & 屯昌 & 5.43 & 琼中 & 6.63 \\
五指山 & 4.56 & 澄迈 & 5.26 & 保亭 & 0.69 \\
文昌 & 2.04 & 临高 & 3.96 & 陵水 & 0.98 \\
琼海 & 2.41 & 儋州 & 6.95 & 白沙 & 7.02 \\
万宁 & 1.33 & 东方 & - & 昌江 & 2.63 \\
\hline
\end{tabular}

在低值区有寒害发生市 (县) 寒害风险较低。形成 根据荔枝寒害纯保险费率, 设计了基于不 此分布特征与海南岛独特的地形是分不开的。海南同免赔额的保险产品, 不同地区农户可根据当 岛地形复杂, 地势四周低平, 中间高䇯, 以五指山、 鹦哥岭为主, 向外围逐级下降。在同一次冷空气南 地实际情况选择不同免赔额的保险产品, 其所 需缴纳的单位面积保险费 $P$ 计算见公式 5 :

$$
P=R \times Q
$$

用, 致使中部山区寒害严重, 南部寒害较轻或无寒

害。因此, 不同地区农户可根据上述结果选择不同 免赔额的保险产品。

3.3 基于纯保费的保险合同设计及示范应用 3. 3.1 气象保险指数合同设计

式中, $Q$ 是投保农户投保的单位面积保险金额。

当保险期内荔枝遭受的寒害满足赔偿条 件时, 则启动保险赔偿。保险公司根据海南省 荔枝寒害保险单位面积的赔付方程（式 6) 进 行赔偿。 
Risk Analysis and Crisis Response in Big Data Era (RAC-16)

$$
I= \begin{cases}y_{r} \times Q & y_{r} \geq F \\ 0 & y_{r}<F\end{cases}
$$

上式中, $I$ 是投保农户可获得的保险赔偿金额; $y_{r}$ 是本年度减产率; $F$ 是免赔率即诱发系数。

为检验保险产品指数的合理性, 选择了海 口和澄迈进行了保险产品的示范应用。根据不 同免赔额的纯保险费率分布和海南政策性农 业保险实际状况，为提高农民投保的积极性， 充分考虑以风险大小定费率, 降低逆选择, 设 计 4 类海南荔枝寒害气象指数保险产品, 分别 为基于 $4 \% 、 6 \% 、 8 \%$ 和 10\%免赔额的产品。 4 类 产品投保户的纯保险费按式 5 计算。投保户在 购买寒害保险产品后, 在保险期内若达到保险 赔偿条件, 则可获得保险赔偿, 保险赔偿金按 式 6 计算。海口和澄迈保险示范产品见表 6 。 3.3 .2 示范应用和误差检验

根据保险合同分别在海口和澄迈开展示
范应用。选择时间段是 2014 年 1-12 月。受 冷空气影响, 2014 年 1 月 20 日始, 海南省各 地气温明显下降, 北部、中部多数市县最低下 降到 $8^{\circ} \mathrm{C}$ 以下。至 24 日, 澄迈和白沙连续 3 天以上最低气温低于 $8^{\circ} \mathrm{C}$, 出现轻度低温阴雨 过程。受强冷空气影响, 2 月 $10 \sim 15$ 日, 海 口、定安、澄迈、临高、儋州、文昌、屯昌、 白沙和琼中等 9 个市县出现持续 $5 \sim 6$ 天的低 温阴雨天气过程, 对果树造成一定的不利影响。

计算的灾情损失: 通过统计 2014 年冬季 的气象资料, 得到了荔枝种植规模较大的 2 个 示范县的寒害指数, 应用公式 2 计算荔枝的单 产减产率。依照各市县采用的保险免赔额标准 及单位面积的物化成本, 分别得到需赔款金额, 示范县海口和澄迈的荔枝单产减产超过了免 赔额, 赔付金额分别为每亩 36.31 元和 54.31 元, 见表 7 。

表 6 荔枝农业气象指数保险示范产品

\begin{tabular}{|c|c|c|c|c|}
\hline 市县名 & 纯保险费率（\%） & 纯保费（元） & 免赔额 & 示范采用的情况 \\
\hline \multirow[t]{4}{*}{ 海口 } & 7.85 & 47.10 & 标准一（免赔额为 4\%) & \multirow{4}{*}{$\bullet$} \\
\hline & 6.79 & 40.74 & 标准二（免赔额为 6\%） & \\
\hline & 6. 08 & 36.48 & 标准三（免赔额为 8\%） & \\
\hline & 5.52 & 33.12 & 标准四（免赔额为 10\%） & \\
\hline \multirow[t]{4}{*}{ 澄迈 } & 8.02 & 48.12 & 标准一（免赔额为 4\%） & \multirow{4}{*}{$\bullet$} \\
\hline & 6.82 & 40.92 & 标准二（免赔额为 6\%） & \\
\hline & 5.96 & 35.76 & 标准三（免赔额为 8\%） & \\
\hline & 5.26 & 31.56 & 标准四（免赔额为 10\%） & \\
\hline
\end{tabular}

备注: 纯保费以每亩保险金额为 600 元计算 (相当于每亩物化成本 600 元)。

\begin{tabular}{|c|c|c|c|c|}
\hline 水果 & 市县 & 样本点 & 气象指数计算减产率 (\%) & 每亩赔款金额 (元) \\
\hline \multirow{2}{*}{ 荔枝 } & 海口 & 红明农场荔枝园 & 6. 051 & 36.31 \\
\hline & 澄迈 & 桥头镇荔枝园 & 9. 051 & 54.31 \\
\hline
\end{tabular}

注: 按每亩物化成本 600 元计算; 开展保险示范。

实际灾情损失: 通过走访 2 个示范县的农 户，对 2014 年的热带果树寒害灾情进行了了 解。农户们普遍反映 2014 年海口和澄迈的灾 情相对较重, 荔枝的开花期遭遇到几次降温, 虽然降温幅度不是很大，但此期的荔枝对温度 变化比较敏感, 低温对后期产量形成还是能够 产生一定影响，初步估计减产在 $10 \%$ 以下，与 模型计算的结果大体相当。考虑到寒害减产不 仅与气象条件相关, 还与种植区的小气候环境、
农业生产水平、灾害防御能力有关, 因此可以 认为对减产率的模拟误差较小, 模型比较准确。

\section{4 结论和讨论}

本研究设计的基于不同免赔额的荔枝寒 害气象指数保险产品和合同, 为不同地区农户 提供了多种可选择的保险产品, 农户可根据实 际情况选择适合当地的保险产品, 提高了本文 确定的保险产品的普适性。此外, 本文设计的 
Risk Analysis and Crisis Response in Big Data Era (RAC-16)

\section{参考文献}

[1]姜慧华. KMV 模型在我国商业银行信用风险度量 中的具体应用-一以工商银行和南京银行为例. 财经论坛. 2016 (05) : 224-227.

[2] 陈晓晨. 基于 KMV 模型分析利率市场化冲击对商 业银行信用风险影. 商, Business. 37(199): 193-194.

[3]杨秀云, 蒋园园, 段珍珍. KMV 模型在我国商业银 行信用风险管理中的适用性分析及实证检验. 财 经理论与实践. 37 (199) : $34-40$.

[4]马美芸. A 股中小上市公司 ST 风险预警一基于 KMV 模型的违约风险实证研究. 上海:华东理工大 学, 2015 .

[5]张涁. 基于模型的融资租赁公司信用风险度量研 究.上海:东华大学, 2014.

[6] 李薇. 基于 KMV 模型的上市公司信用风险度量研 究 $\mathrm{A}$ 股市场房地产行业的实证研究. 成都: 西南 财经大学，2013.

[7] 凌江怀, 刘燕媚. 基于 KMV 模型的中国商业银行 信用风险实证分析-D以 10 家上市商业银行为 例. 华南师范大学学报 (社会科学版). (05) : 142-148.

[8] Y. Yang, L. Li, Z.F. Zhou, W.Y. Fei. The Research on applicability of amended kmv model with different industries. Journal of Risk Analysis and Crisis Response, 2013,3(1):27-33.

[9] 爱德华 - 阿特曼（Edward Altman）. 财务比率、 判别分析及公司破产预测. 财务杂志. 1968,22.

[10] 谢赤、赖琼琴、王纲金．基于 JD-KMV 模型的 上市公司信用风险度量-——个区域金融视角 下的实证研究. 经济地理. 2014, 34(6):137-141. 